\title{
Frequency of Different Stages of Pelvic Organ Prolapse and Factors Leading to it
}

\author{
Kouser Karim* and Ayesha Khan \\ Department of Obstetrics and Gynaecology, Dow University of Health Sciences, Karachi, Pakistan.
}

\begin{abstract}
Introduction: Pelvic Organ Prolapse (POP) is an important gynecological morbidity. An increasingly popular classification system for this disease is the Pelvic Organ Prolapse Quantification System (POP-Q). This study was intended to initiate an information campaign, preventive care management and early treatment to reduce this public and social health problem.
\end{abstract}

Subject and Methods: A Cross sectional study was carried out on 197 women with complaints of something coming out of vagina or heaviness in pelvis. General physical and standard pelvic examination in dorsal lithotomy position was performed for the diagnosis of pelvic organ prolapse.

Results: Frequency of various stages of pelvic organ prolapse using Pelvic Organ Prolapse Quantification System (POP-Q) in women was observed as stage 0 (10.2\%); stage I (9.69\%); stage II (52.55\%) and stage III (27.55\%). Rate of stage of pelvic organ prolapse was also not significant with parity, menopausal status and hormone replacement therapy while effect of increase abdominal pressure on the POP-Q stage was also statistically significant $(\mathrm{p}=0.0005)$.

Conclusion: In conclusion, increased abdominal pressure and overweight clearly confers a risk for pelvic organ prolapse. Risk factors (age, parity, menopausal status and hormone replacement therapy) may influence the stages of POP, however the relationship between these factors and different stages has not been clearly understood.

Keywords: Abdominal pressure, Hormone replacement therapy, Menopausal status, Pelvic organ prolapse, POP-Q system. doi.org/10.21089/njhs.23.0109

\section{INTRODUCTION}

Pelvic Organ Prolapse (POP) is an important gynecological morbidity with multifactorial etiology that badly compromises health and quality of women if not treated timely and appropriately. The purpose of this study was to provide an overview of frequency and risk factors for pelvic organ prolapse so that they can be avoided and approached in a standard manner. The global prevalence of genital prolapse is estimated to be $2-20 \%$ in women aged under 45 years [1] and in older women incidence has been reported as higher as $39.8 \%$ [2]. Upto $50 \%$ of all parous women aged $15-97$ years have some degree of vaginal wall laxity with $10-20 \%$ symptomatic. Life time risk of undergoing surgery is $11 \%$. About $22 \%$ women in Pakistan and 19\% in Karachi are identified with symptomatic prolapse [3].

As prolapse has been recognized for more than one hundred years, different systems have been proposed for its staging; however, none has so far recommended to be definite. The latest addition to the group is Pelvic Organ Prolapse Quantification System (POP-Q) that has become increasingly

*Address correspondence to this author at the Department of Obstetrics and Gynaecology, Dow University of Health Sciences, Karachi, Pakistan.

E-mail: kouser@outlook.com popular all over and it is internationally recognized by International Continence Society (ICS) and American Urogynaecologic Society (AUGS) [4]. Standardization subcommittee of the ICS created the POP-Q system in 1996. Advantage of POP-Q system assessment is its good reproducibility when different doctors do the assessment. This makes it easy to compare the results of different clinical studies. In POP-Q system, fixed reference point used for measurement is hymenal ring. Specific measurements at nine sites are recorded in a tic-tac-toe grid so inter-observer agreement is good. It has been shown that the routine use of the POP-Q system decreases significantly the amount of time needed to collect the desired data [5].

There are well known risk factors for POP including age, birth, trauma, chronic increase in intra-abdominal pressure (obesity, chronic constipation, chronic coughing, chronic obstructive pulmonary disease, heavy lifting), smoking, menopause, estrogen deficiency, genetic factors, prior surgery, myopathy and collagen abnormalities $[2,6,7]$. These risk factors vary from patient to patient and can be influenced by race. Precise etiology of uterovaginal prolapse is not known but likely to be multifactorial. The severity of prolapse may vary with different risk factors [8-10]. 
Risk factors may influence the stages of POP however, the relationship between these factors and the stage III has not been clearly understood. Due to extended life expectancy and expanding elderly population, prolapse is now an increasingly prevalent condition. So, the aim of study was to evaluate frequency of various stages of POP-Q system and factors leading to it. This would be helpful in initiating information campaign, preventive care management and early treatment to reduce this public and social health problem.

\section{MATERIALS AND METHODS}

\section{Objective}

1.To determine the frequency of various stages of POP using POP-Q system in women coming with symptoms and signs of uterovaginal prolapse in Gynecology Unit II, Civil Hospital, Karachi.

2.To determine various factors leading to different stages of POP.

Study Design: Cross-sectional study.

Setting: Department of Obstetrics and Gynecology Unit II, Civil Hospital, Karachi, tertiary care hospital.

Duration: Six months i.e. January 2013 to June 2013.

Sample Size (n): 196 patients; using open-epi sample size calculator with $\mathrm{P}=47 \%, \mathrm{D}=7 \%$ and $\mathrm{CI}=95 \%$. $\mathrm{P}=47 \%$, according to study by Garshasbi A [7], was taken maximum percentage of stage 0 .

Sampling Technique: Non-probability (consecutive).

\section{SAMPLE SELECTION}

\section{Inclusion Criteria}

1. Women with complaints of something coming out of vagina or heaviness in pelvis irrespective of age, parity and duration of symptoms

2. Women with voiding difficulties.

3. Women with backache.

4. Women with stress incontinence, that is loss in small amount of urine related to increase in abdominal pressure.

5. Women with inefficient rectal emptying.

\section{Exclusion Criteria}

1. Uterovaginal prolapse with pregnancy.

2. Prolapse with malignancy.

\section{DATA COLLECTION PROCEDURE}

The study population consisted of patients who visited Gynae Unit II outpatient department. Women who fulfill selection criteria were identified. After obtaining an informed consent from identified patients, a detail history was taken and the risk factors were identified. General physical and standard pelvic examination in dorsal lithotomy position was performed. After inspection, the labia were separated and any prolapse was noted. Prolapse was graded by using the POP-Q system. Plane of hymen is defined as zero. Points above hymen were given negative number and points below hymen positive number. All the measurements were made in centimeters. Stages of prolapse was assessed while patient straining. Sims speculum was used to examine prolapse. All the measurements were made by using a marked ayre's spatula. The findings were noted on proforma attached as an annex. The presence of risk factors and severity of degree according to POP-Q system was determined.

\section{POP-Q Classification}

Stage 0: No prolapse is demonstrated

Stage I: Most distal portion of prolapse is more than $1 \mathrm{~cm}$ above the level of hymen.

Stage II: Most distal portion of the prolapse is situated between $1 \mathrm{~cm}$ below or above hymen.

Stage III: The most distal portion of prolapse is more than $1 \mathrm{~cm}$ blond the plane of hymen but everted at least $2 \mathrm{~cm}$ less then total vaginal length.

Stage IV: Complete eversion or eversion at least within $2 \mathrm{~cm}$ of the total length of the lower genital tract is demonstrated.

\section{DATA ANALYSIS PROCEDURE}

All statistical analysis was performed using statistical packages for social science version 10 (SPSS Inc., Chicago, IL). Descriptive analyses of qualitative and quantitative variables were performed. Quantitative variable like age, BMI, duration of labour and duration of admission to delivery time was presented as mean and standard deviation. Qualitative variables like menopause, parity, HRT and stage of POP were presented as frequency and percentage. Effect modifiers like BMI was controlled by stratification techniques and stage and factors leading to stage of POP were evaluated through chi-square test. $\mathrm{p} \leq 0.05$ was considered as significant.

\section{RESULTS AND DISCUSSION}

A total of 197 women with complaints of something coming out of vagina or heaviness in pelvis were included in this study. Most of the patients were 31 to 60 years of age. Age distribution of women is presented in (Fig. 1). The average age and BMI of the women were $45.95 \pm 13.15$ years and $23.43 \pm 2.63 \mathrm{~kg} / \mathrm{m}^{2}$ respectively. Similarly, average duration of labor and admission to delivery internal are also shown in (Table 1). One hundred and seven women (54.59\%) had multiparity, $79(40.31 \%)$ had grand multiparty and 10 $(5.10 \%)$ had primipara (Fig. 2). Regarding the menopausal 
status, 66.84\% women had pre-menopausal and 33.16\% women had post-menopausal status (Fig. 3). Increased abdominal pressure was as observed in $43.88 \%$ (86/197) women (Fig. 4). Similarly, HRT was done in $5.1 \%(10 / 197)$ women (Fig. 5). Frequency of various stages of POP using
POP-Q system in women was observed as stage $0,10.2 \%$; stage I, $9.69 \%$; stage II, $52.55 \%$ and stage III, $27.55 \%$ as presented in (Fig. 6). Stage IV was not observed in this study.

Table 1. Descriptive statistics of characteristics of women.

\begin{tabular}{|c|c|c|c|c|c|c|c|c|}
\hline & \multirow{2}{*}{ Mean } & \multicolumn{2}{|c|}{ 95\% Confidence Interval for Mean } & \multirow{2}{*}{ Median } & \multirow{2}{*}{ Std. Deviation } & \multirow{2}{*}{ Minimum } & \multirow{2}{*}{ Maximum } & \multirow{2}{*}{$\begin{array}{c}\text { Interquartile } \\
\text { Range }\end{array}$} \\
\hline & & Lower Bound & Upper Bound & & & & & \\
\hline Age (years) & 45.95 & 44.10 & 47.80 & 45 & 13.15 & 15 & 80 & 20 \\
\hline BMI $\left(\mathrm{kg} / \mathrm{m}^{2}\right)$ & 23.43 & 23.06 & 23.80 & 24 & 2.63 & 18 & 30 & 3 \\
\hline Average of duration of Labour & 13.57 & 12.89 & 14.25 & 12 & 4.68 & 8 & 30 & 5 \\
\hline Average Admission to delivery Interval & 21.30 & 20.28 & 22.32 & 20 & 5.98 & 10 & 48 & 6 \\
\hline
\end{tabular}

Table 2. Factors leading to different stages of pelvic organ prolapsed.

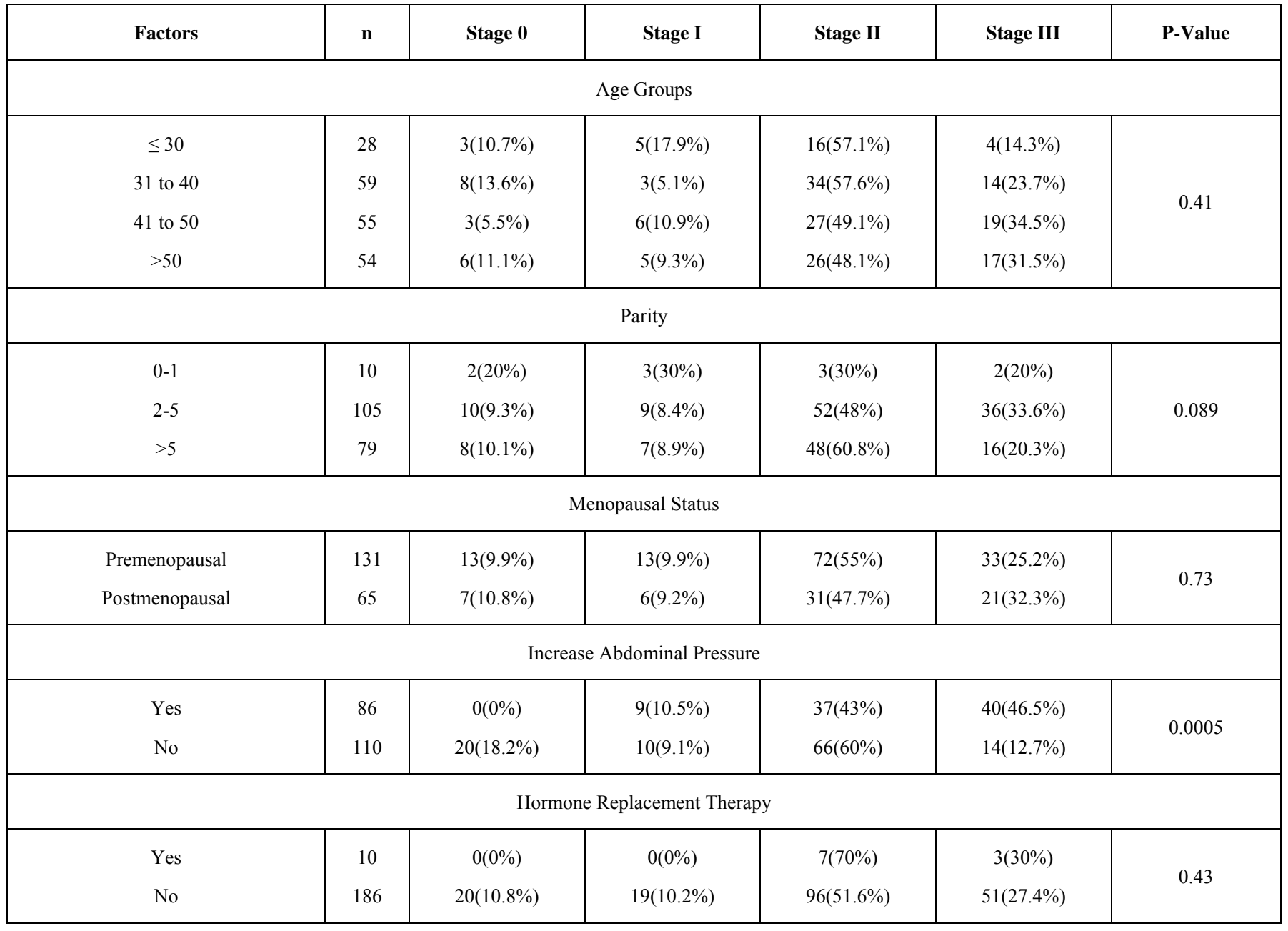




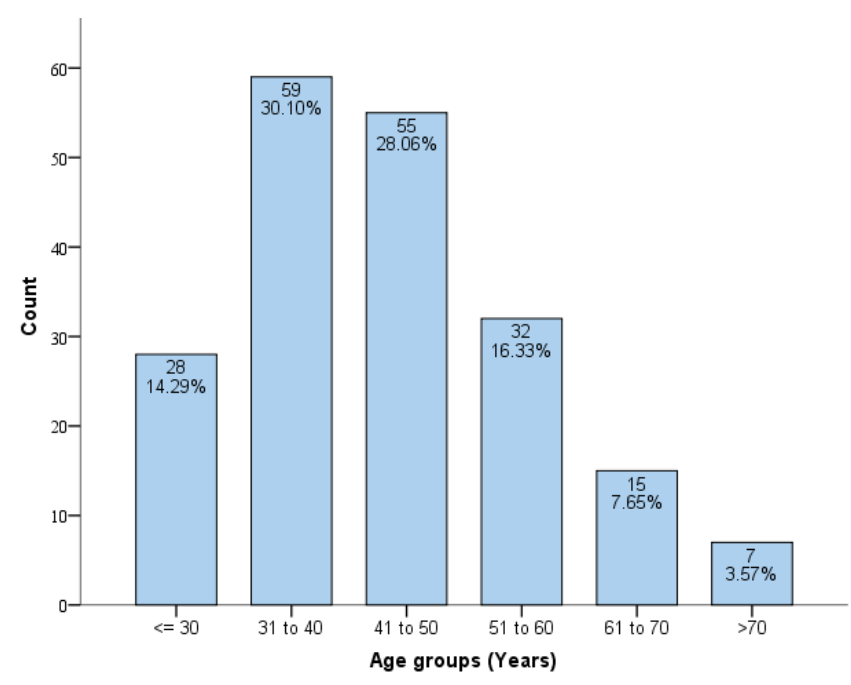

Fig. (1). Age distribution of the patients $(n=196)$.

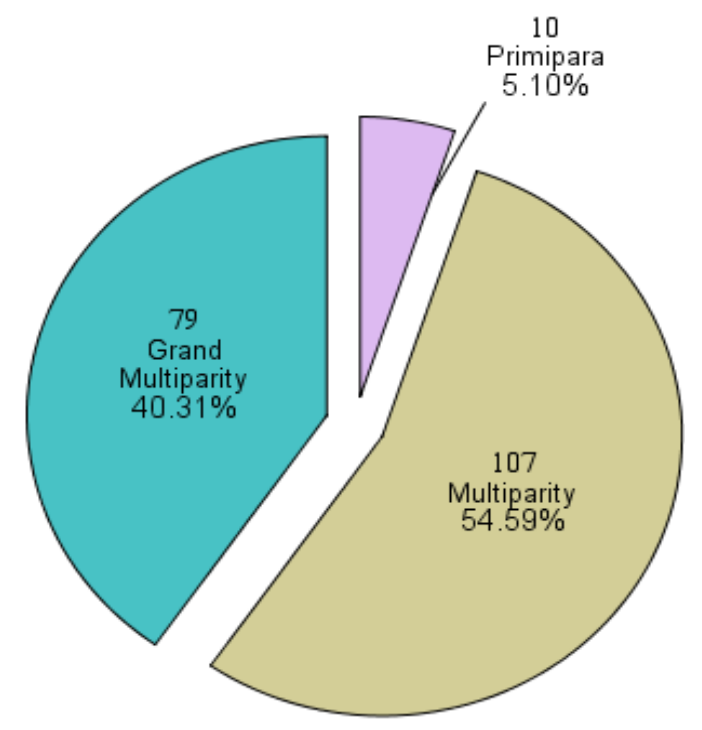

Fig. (2). Parity status of the patients $(n=196)$.

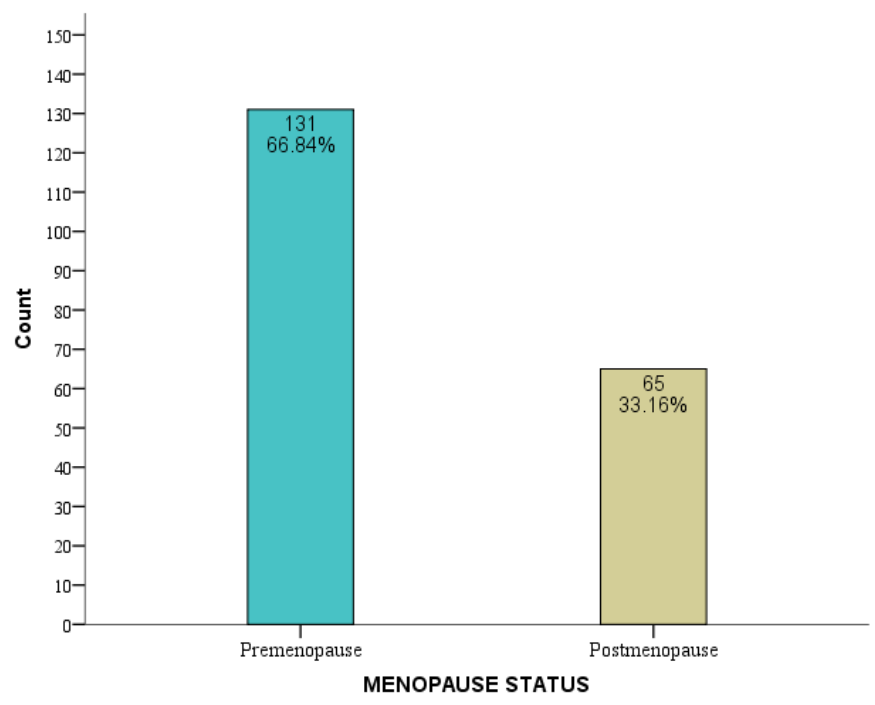

Fig. (3). Menopausal status of women ( $\mathrm{n}=196)$.
In a population-based Dutch study, the prevalence of POP by POP-Q staging was as follows: stage $0(25.0 \%)$, stage I $(36.5 \%)$, stage II $(33 \%)$, stage III $(5.0 \%)$, and stage IV $(0.5 \%)$ [11].

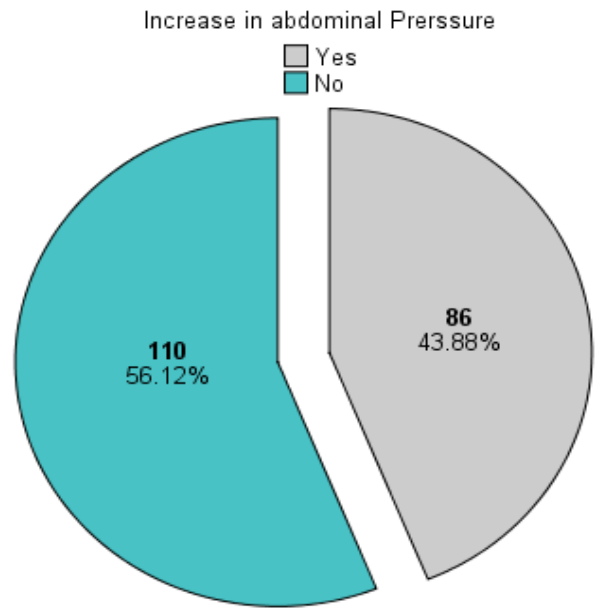

Fig. (4). Increase abdominal pressure of women $(n=196)$.

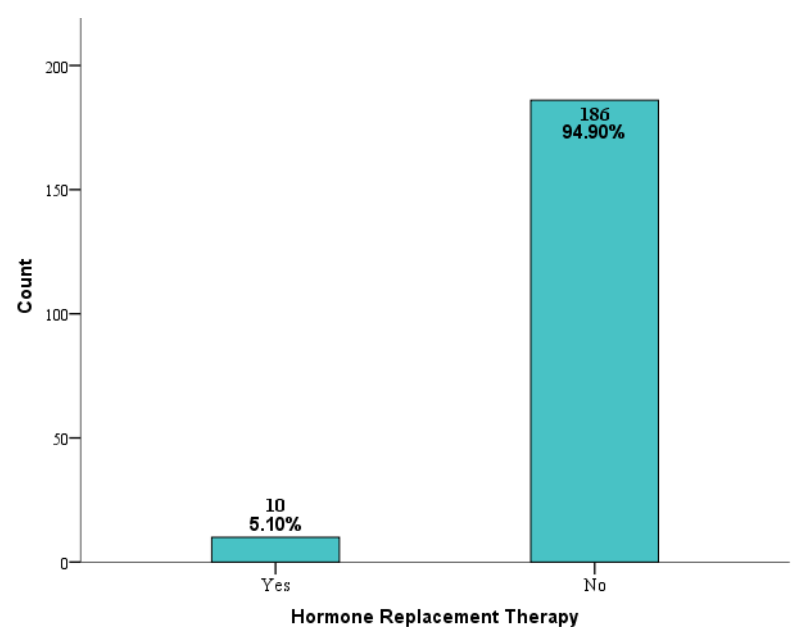

Fig. (5). Hormone replacement therapy $(n=196)$.

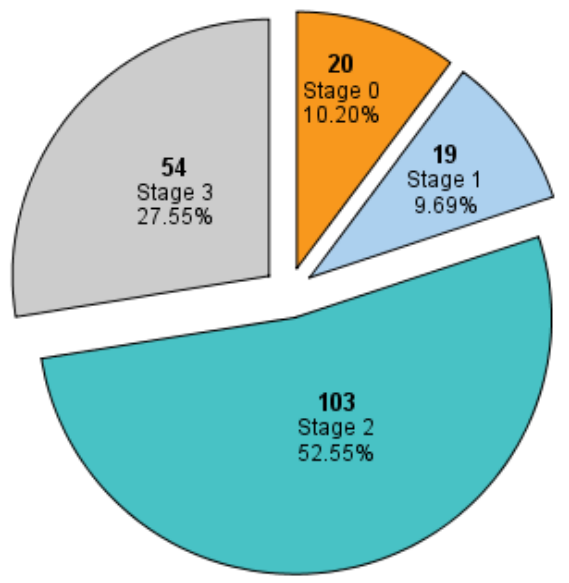

Fig. (6). Frequency of various stages of pelvic organ prolapse using Pelvic Organ Prolapse Quantification System (POP-QS) in women ( $\mathrm{n}=196)$. 
Table 3. Frequency of various stages of pelvic organ prolapse for normal and overweight BMI.

\begin{tabular}{|c|c|c|c|c|c|c|}
\hline BMI & n & Stage 0 & Stage I & Stage II & Stage III & P-Value \\
\hline Normal (18-24) & 124 & $17(13.7 \%)$ & $10(8.1 \%)$ & $62(50 \%)$ & $35(28.2 \%)$ \\
\hline Overweight (25-30) & 72 & $3(4.2 \%)$ & $9(12.5 \%)$ & $41(56.9 \%)$ & $19(26.4 \%)$ \\
\hline
\end{tabular}

Chi-square $=5.46$.

Table 4. Factors leading to different stages of pelvic organ prolapse for normal BMI women.

\begin{tabular}{|c|c|c|c|c|c|c|}
\hline Factors & $\mathbf{n}$ & Stage 0 & Stage I & Stage II & Stage III & P-Value \\
\hline \multicolumn{7}{|c|}{ Age Groups } \\
\hline 31 to 40 & 35 & $6(17.1 \%)$ & $2(5.7 \%)$ & $19(54.3 \%)$ & $8(22.9 \%)$ & \multirow{2}{*}{0.68} \\
\hline 41 to 50 & 29 & $3(10.3 \%)$ & $2(6.9 \%)$ & $13(44.8 \%)$ & $11(37.9 \%)$ & \\
\hline \multicolumn{7}{|c|}{ Parity } \\
\hline $0-1$ & 8 & $2(25 \%)$ & $1(12.5 \%)$ & $3(37.5 \%)$ & $2(25 \%)$ & \multirow{3}{*}{0.78} \\
\hline $2-5$ & 65 & $8(12.3 \%)$ & $6(9.2 \%)$ & $30(46.2 \%)$ & $21(32.3 \%)$ & \\
\hline$>5$ & 51 & $7(13.7 \%)$ & $3(5.9 \%)$ & $29(56.9 \%)$ & $12(23.5 \%)$ & \\
\hline Postmenopausal & 49 & $6(12.2 \%)$ & $6(12.2 \%)$ & $20(40.8 \%)$ & $17(34.7 \%)$ & 0.21 \\
\hline \multicolumn{7}{|c|}{ Increase Abdominal Pressure } \\
\hline Yes & 51 & $0(0 \%)$ & $4(7.8 \%)$ & $24(47.1 \%)$ & $23(45.1 \%)$ & \multirow{2}{*}{0.0005} \\
\hline No & 73 & $17(23.3 \%)$ & $6(8.2 \%)$ & $38(52.1 \%)$ & $12(16.4 \%)$ & \\
\hline \multicolumn{7}{|c|}{ Hormone Replacement Therapy } \\
\hline Yes & 6 & $0(0 \%)$ & $0(0 \%)$ & $4(66.7 \%)$ & $2(33.3 \%)$ & 0.62 \\
\hline
\end{tabular}

In a study conducted by Garshasbi A [12], he found that the overall distribution of pelvic organ prolapse was as follows: stage 0 (47\%); stage I (23.1\%); stage II (18.3\%) and stage III (11.6\%). In a study by Kim CM [2], distribution of POP-Q stages were as follows: stage II (25\%), stage III (55\%), stage IV $(20 \%)$.

Various factors leading to different stages of POP is presented in (Table 2). In this study, an insignificant trend between stages of POP and age of the patients was observed. Similarly, rate of stage of POP was also not significant with parity, menopausal status and HRT (Table 2), while, +ve effect of increased abdominal pressure on the POP-Q stage was also statistically significant $(\mathrm{p}=0.0005)$.
In the study by Kim CM [2], he found that age, parity, menopause and Hormone Replacement Therapy (HRT) were significantly associated with stage of POP and age and parity increases by a statistically significant level as the disease becomes more severe. He found that age $>70$ years, parity $>$ 3 and menopausal status were significant risk factors for POP [2].

As observed by Kim CM [2], the mean age of 54.40 years was associated with stage II of POP-Q system, mean age of 61.59 years was associated with stage III and mean age of 64.25 years was associated with stage IV. Parity of 3.12 was associated with stage II, parity of 3.83 was associated with stage III and parity of 4.04 was associated with stage IV. 
$61.59 \%$ of women without HRT were associated with stage II, $89.4 \%$ of women without HRT were associated with stage
III and $90.9 \%$ of women were associated with stage IV [2].

Table 5. Factors leading to different stages of pelvic organ prolapse for overweight women.

\begin{tabular}{|c|c|c|c|c|c|c|}
\hline Factors & $\mathbf{n}$ & Stage 0 & Stage I & Stage II & Stage III & P-Value \\
\hline \multicolumn{7}{|c|}{ Age Groups } \\
\hline$\leq 30$ & 8 & $0(0 \%)$ & $4(50 \%)$ & $3(37.5 \%)$ & $1(12.5 \%)$ & \multirow{4}{*}{0.05} \\
\hline 31 to 40 & 24 & $2(8.3 \%)$ & $1(4.2 \%)$ & $15(62.5 \%)$ & $6(25 \%)$ & \\
\hline 41 to 50 & 26 & $0(0 \%)$ & $4(15.4 \%)$ & $14(53.8 \%)$ & $8(30.8 \%)$ & \\
\hline$>50$ & 14 & $1(7.1 \%)$ & $0(0 \%)$ & $9(64.3 \%)$ & $4(28.6 \%)$ & \\
\hline \multicolumn{7}{|c|}{ Parity } \\
\hline $0-1$ & 2 & $0(0 \%)$ & $2(100 \%)$ & $0(0 \%)$ & $0(0 \%)$ & \multirow{3}{*}{0.005} \\
\hline $2-5$ & 42 & $2(4.8 \%)$ & $3(7.1 \%)$ & $22(52.4 \%)$ & $15(35.7 \%)$ & \\
\hline$>5$ & 28 & $1(3.6 \%)$ & $4(14.3 \%)$ & $19(67.9 \%)$ & $4(14.3 \%)$ & \\
\hline \multicolumn{7}{|c|}{ Menopausal Status } \\
\hline Premenopausal & 56 & $2(3.6 \%)$ & $9(16.1 \%)$ & $30(53.6 \%)$ & $15(26.8 \%)$ & \multirow{2}{*}{0.34} \\
\hline Postmenopausal & 16 & $1(6.3 \%)$ & $0(0 \%)$ & $11(68.8 \%)$ & $4(25 \%)$ & \\
\hline \multicolumn{7}{|c|}{ Increase Abdominal Pressure } \\
\hline Yes & 35 & $0(0 \%)$ & $5(14.3 \%)$ & $13(37.1 \%)$ & $17(48.6 \%)$ & \multirow{2}{*}{0.005} \\
\hline No & 37 & $3(8.1 \%)$ & $4(10.8 \%)$ & $28(75.7 \%)$ & $2(5.4 \%)$ & \\
\hline \multicolumn{7}{|c|}{ Hormone Replacement Therapy } \\
\hline Yes & 4 & $0(0 \%)$ & $0(0 \%)$ & $3(75 \%)$ & $1(25 \%)$ & \multirow{2}{*}{0.81} \\
\hline No & 68 & $3(4.2 \%)$ & $9(13.2 \%)$ & $38(55.9 \%)$ & $18(26.5 \%)$ & \\
\hline
\end{tabular}

Garshasbi A [12] found that in age group 18-29 years, frequency of stage 0 is $72.8 \%$, stage I is $21.3 \%$, stage II is $5.9 \%$ and stage III is $0 \%$.In age group 30- 39 frequency of stage 0 is $46.6 \%$, stage I is $27 \%$, stage II is $15 \%$ and stage III is $11.2 \%$. In age group 40-49 years, frequency of stage 0 is $33.7 \%$, stage I is $29.2 \%$, stage II is $25 \%$ and stage III is $20 \%$. In age group 50 or more frequency of stage 0 is $17.6 \%$, stage I is $33.9 \%$, stage II is $26.7 \%$ and stage III is $21.4 \%$. He also found that in para 0 , frequency of stage 0 is $94.1 \%$, stage $I$ is $5.9 \%$, stage II is $0 \%$ and stage III is $0 \%$. In para $1-3$, frequency of stage 0 is $52.6 \%$, stage I is $19.7 \%$, stage II is $15.3 \%$ and stage III is $6.2 \%$.

In a study by Perveen S [3], around $50 \%$ of women with uterovaginal prolapse were $>50$ years of age and $75 \%$ were grand multipara. Haque S [6], found that frequency of symptomatic prolapse was $11 \%$, among which $44.18 \%$ of patients were of $<40$ years of age and $55.8 \%$ were of $>40$ years of age. $63.95 \%$ of patient had parity of 5 or above and $32.56 \%$ had parity of 4 and below. However, none of these studies had shown the severity of prolapse in patients with different risk factors.

Stratification analysis with respect to normal and overweight women is also presented (Table 2). Frequency of POP-Q stages was not significant between normal and overweight women (Table 3). Various factors leading to different stages of POP were also evaluated for normal and overweight women as presented in (Table 4 and 5). For normal women (BMI 18-24), POP-Q stages was insignificant with age, parity, menopausal status and HRT while, increased abdominal pressure was significantly associated with stages $(\mathrm{p}=0.0005)$ $[13,14]$. For overweight women (BMI 25-30), POP-Q stages were statistically significant with age, parity, menopausal status (Table 5).

\section{CONCLUSION}

In conclusion, increase abdominal pressure and overweight clearly confers a risk for POP. Risk factors (age, parity, menopausal status and HRT) may influence the stages of 
POP. However, the relationship between these factors and the stage has not been clearly understood.

Preventive care management and early treatment will reduce this public and social health problem. Small family size and delivery under supervision should be adopted to reduce the risk of POP.

\section{CONFLICT OF INTEREST}

Declared none.

\section{ACKNOWLEDGEMENT}

Declared none.

\section{REFERENCES}

[1] Bodner-Adler B, Shrivastava C, Bodner K. Risk factors for uterine prolapse in Nepal. Int. Urogynecol. J., 2007; 18(11): 1343-6. DOI: 10.1007/s00192-007-0331-y

[2] Kim CM, Jeon MJ, Chung DJ, Kim SK, Kim JW, Bai SW. Risk factors for pelvic organ prolapse. Int. J. Gynaecol. Obstet., 2007; 98(3): 248-51. DOI: 10.1016/j.ijgo.2007.02.019

[3] Perveen S, Tayyab S, Mumtaz N. Pelvic organ prolapse in peri urban area of Karachi. Med. Channel., 2006; 12(4): 17-20.

[4] Persu C, Chapple CR, Cauni V, Gutue S, Geavlete P. Pelvic organ prolapse quantification system (POP-Q): a new era in pelvic prolapse staging. J. Med. Life., 2011; 4(1): 75-81.

[5] Dhama V, Chaudhary R, Singh S, Singh M. Evaluation of pelvic organ prolapse by standardized POP $\mathrm{Q}$ system for vaginal hysterectomy. Int. J. Reprod. Contracept. Obstet. Gynecol., 2017; 6(6): 2584-2588. DOI: $10.18203 / 2320-1770$. ijrcog20172356
[6] Haque S, Khan A. Frequency and pelvic symptoms in women with pelvic organ prolapse. Pak. J. Surg., 2010; 26(1): 50-4.

[7] Doshani A, Teo RE, Mayne CJ, Tincello DG. Uterine prolapse. BMJ, 2007; 335: 819-23. DOI: 10.1136/bmj.39356.604074.be

[8] Whitcomb EL, Rortveit G, Brown JS, Creasman JM, Thom DH, Van Den Eeden SK, et al. Racial differences in pelvic organ prolapse. Obstet. Gynecol., 2009; 114(6): 1271-7. DOI: 10.1097/aog.0b013e3181bf9cc8

[9] Lei L, Song Y, Chen R. Biomechanical properties of prolapsed vaginal tissue in pre and postmenopausal women. Int. Urogynecol. J., 2007; 18(6): 603-7. DOI: 10.1007/s00192-006-0214-7

[10] Rodrigues AM, de oliveira LM, Martins Kde F, Del Roy CA, Sartori MC, Girao MJ. Risk factors for genital prolapse in a Brazilian population. Rev. Bras. Gynecol. Obstet., 2009; 31(1): 1721.

[11] Slieker-ten Hove MC, Pool-Goudzwaard AL, Eijkemans MJ, Steegers-Theunissen RP, Burger CW, Vierhout ME. The prevalence of pelvic organ prolapse symptoms and signs and their relation with bladder and bowel disorders in a general female population. Int. Urogynecol. J., 2009; 20(9): 1037-45. DOI: 10.1007/s00192-009-0902-1

[12] Garshabi A, Faghih-Zadeh S, Falah N. The status of pelvic supporting organs in a population of Iranian women 18-68 years of age and possible risk factors. Arch. Iran. Med., 2006; 9(2): 124-8.

[13] Wang Y, Jiang J, Han J. A review of the pelvic organ prolapse quantification system in China. Int. Urogynecol. J., 2016; 27(2): 287-90. DOI: $10.1007 / \mathrm{s} 00192-015-2830-6$

[14] Fatima Q, Razzaqe H , Kashif M , Aslam F. Association of parity and pelvic organ prolapse. JRMC, 2016; 20(S-1): 104-8. 